\title{
Notas sobre el catolicismo social cusqueño: E1 canónigo Isaías Vargas y sus Apuntes críticos sobre asuntos indigenistas ${ }^{1}$
}

\section{Notes on Cuzco social Catholicism: Canon Isaias Vargas and his critical notes on indigenist issues}

Ricardo Cubas Ramacciotti ${ }^{2}$

Universidad de los Andes, Chile

\section{Resumen}

El objetivo del artículo es dar a conocer el pensamiento social del padre Isaías Vargas Bueno en el contexto del debate indigenista peruano de la primera mitad del siglo XX. Habiendo sido canónigo de Cusco y un cercano colaborador del obispo Pedro Farfán, una parte importante de su labor pastoral estuvo ligada al estudio de los problemas del mundo rural en el sur andino y al desarrollo de un perseverante activismo en favor de los derechos nativos durante más de cuatro décadas. Vargas se inscribió dentro de una corriente social-cristiana que, siendo crítica del marxismo y del liberalismo, planteó un conjunto de propuestas reformistas para enfrentar la cuestión indígena.

1 Este trabajo pudo realizarse gracias al financiamiento del Fondo de Ayuda a la Investigación (FAI: IN0TO201036 HIS-001-10) que me otorgó la Dirección de Investigación de Universidad de los Andes (Santiago de Chile).

2 Doctor en Historia, University of Cambridge, Reino Unido. Contacto: ricardocubasr@gmail.com 
Palabras clave: Indigenismo, Siglo XX, Perú, Isaías Vargas Bueno, Cusco

$$
* * *
$$

\section{Abstract}

The objective of the article is to make known the social thought of Father Isaías Vargas Bueno in the context of the Peruvian indigenist debate during the first half of the twentieth century. As a canon of Cusco and a close collaborator of Bishop Pedro Farfán, an important part of his pastoral work was linked to the study of the problems of the rural world in the Andean south and to the development of a persevering activism in favor of the native rights for more than four decades. Vargas participated in a social-Christian current that, being critical of the Marxism and the liberalism, raised a set of reformist proposals to benefit the indigenous population.

Keywords: Indigenism, Twentieth century, Peru, Isaías Vargas Bueno, Cusco

El presente trabajo busca dar a conocer el pensamiento indigenista del canónigo cusqueño Isaías Vargas Bueno, un personaje prácticamente olvidado pero cuyos escritos son un testimonio de las ideas sociales esgrimidas por parte del clero peruano frente a la pobreza y marginación que afectaban a gran parte de las poblaciones originarias del país. En particular, el objetivo es analizar dos de sus obras más representativas: Apuntes críticos sobre asuntos indigenistas (1946) y $R e-$ copilaciones psico-sociológicas de mis apuntes críticos sobre asuntos indigenistas (1948). Ambos textos son compilaciones de ensayos 
que permiten rastrear la participación de monseñor Vargas ${ }^{3}$ en el debate sobre el problema del indio a lo largo de cuatro décadas. Las cuestiones tratadas incluyen estudios sobre los problemas del mundo rural peruano, denuncias frente a los abusos contra las comunidades campesinas, propuestas de cambios institucionales y sociales, y diversas interpretaciones sobre la historia y la cultura del sur andino. En este artículo, después de describir someramente el ambiente religiosoeclesial de Cusco, se hace un breve esbozo de la vida y de las ideas sociales del presbítero.

\section{$\mathrm{El}$ ambiente religioso de Cusco a principios del siglo XX}

Como se describe en las Memorias de Luis E. Valcárcel, el Cusco donde creció y se formó Isaías Vargas durante la primera mitad del siglo XX estuvo marcado por una arraigada religiosidad $^{4}$, que se exteriorizaba en la participación masiva del pueblo en diversas festividades, entre las cuáles destacaban la Semana Santa ${ }^{5}$ y el Corpus Christi. En estos aconte-

3 Cabe aclarar que el padre Vargas no fue obispo y que el título de monseñor se le otorgó por ser canónigo de la catedral de Cusco y vicario general de las diócesis.

4 "La profunda religiosidad de los cusqueños podía apreciarse en la masiva asistencia a las iglesias, no solamente a las misas dominicales sino también cotidianamente" (Valcárcel 1981: 64).

5 "La Semana Santa era el momento culminante del año en materia de celebraciones religiosas. El acto principal era la procesión del día lunes, en que el Señor de los Temblores recorría la Plaza de Armas entre las invocaciones de los fieles y las rogativas en quechua de la gente del pueblo... Blancos, mestizos e indios se juntaban en las calles participando todos de un fervor realmente conmovedor inclusive para quienes, como yo, no era religioso ni mucho menos. Los indios acudían desde sus provincias, agrupados por parroquias, y antes de que el Señor apareciera, se reunían 
cimientos se mezclaban las manifestaciones públicas de sincera piedad cristiana ${ }^{6}$ con excesos comunes en estas fiestas, los que eran censurados tanto por eclesiásticos como por los críticos de la Iglesia católica, aunque con distintos móviles y razones (Klaiber 1988: 263).

Esta religiosidad contrastaba con el anticlericalismo que había calado en un sector de la intelectualidad y de los universitarios cusqueños, especialmente influenciados por las ideas de Manuel González Prada ${ }^{7}$. Paralelamente, se desarrolló en Cusco y Puno un indigenismo que buscó la reivindicación del indio y que, en muchos casos, se caracterizó por su carácter revolucionario, su rechazo de la tradición hispana y occidental, y su acentuado sentimiento regionalista ${ }^{8}$.

en gran número en la Plaza de Armas, frente al atrio de la Catedral. Cuando las andas aparecían se producía una inmensa manifestación de duelo. Poco a poco la imagen se hundía en la multitud entre un coro de ayes y llantos" (Valcárcel 1981: 58-59).

6 "Recuerdo un suceso realmente interesante. Cierta vez, justamente en una iglesia de Urubamba, pude observar a un grupo de mujeres indígenas escuchando con mucha unción un sermón en castellano. Lo curioso era que esa gente no entendía sino el quechua. Cuando me acerqué a preguntar a una de ellas por qué atendía un sermón que no comprendía se limitó a responderme: "nuestra alma está oyendo"(Valcárcel 1981: 69).

7 "La excepción a esta religiosidad fue introducida por la juventud, porque primero a fines del siglo pasado, siguiendo las ideas de Manuel González Prada, muchos jóvenes se tornaron anticlericales. Nuestra actitud universitaria tampoco podía calificarse de religiosa, puesto que en su mayoría éramos de ideas liberales. De ahí que una buena parte de la alta sociedad quedara un tanto al margen de la vida religiosa" (Valcárcel 1981: 58).

8 Algunos de los autores más influyentes fueron José Ángel Escalante (1882-1965), José Uriel García (1894-1965) y Luis E. Valcárcel (18911987) en Cusco, y José Antonio Encinas (1888-1958) en Puno (González 2012: 35-36). Hay algunos trabajos que han analizado y discutido las ideas y acciones del indigenismo del sur andino peruano desde el punto de vista de los intelectuales (Deustua y Renique 1981; De la Cade- 
Por su parte, el clero cusqueño, al igual que el resto de la Iglesia en el país, desde principios del siglo XX había logrado cierta renovación caracterizada por un énfasis en la formación y en la vida espiritual de sus miembros, y por un mayor dinamismo pastoral y social. A pesar de ello, se conservaban algunos problemas que se arrastraban desde el siglo anterior $^{9}$. Por lo general, se observaba una cercanía de los curas diocesanos y de los miembros de las órdenes religiosas hacia los sectores populares. Por ejemplo, muchos de los sacerdotes predicaban en quechua y desarrollaron diversas iniciativas sociales y culturales ${ }^{10}$.

na 2004; Lynch 1979). Por cierto, la preocupación por la cuestión indígena no solo se había concentrado en el sur peruano, sino que era parte importante del discurso de políticos, activistas e intelectuales de diversas tendencias en todo el país. Han sido ampliamente estudiadas las polémicas al respecto entre José Carlos Mariátegui y Víctor Raúl Haya de la Torre (Chang-Rodríguez 2009) o las actividades de la Asociación Pro-Indígena lideradas por Pedro Zulen y Dora Mayer (Katalin 2007) y del intenso activismo político del Comité Central Pro-Derecho Indígena Tahuantinsuyo (Arroyo 2004; Álvarez-Calderón 2009).

9 La labor de moralización del clero en muchos casos no resultó fácil. Valcárcel relata que "Resultaba muy singular cierta práctica bastante difundida entre los curas cusqueños de la época. Muchos de ellos vivían con sus familias, sus supuestos sobrinos y una aparente prima, madre de aquellos. Sin embargo, la gente sabía que esos familiares no eran sino hijos y conviviente del clérigo. Todo esto ocurría con la máxima desfachatez". Aparentemente, esta situación afectó al canónigo Mariano N. García Bueno. Según Valcárcel, fue hijo de un cura y medio hermano de Isaías Vargas. Sin embargo, según la versión de Vargas, Mariano García fue hijo legítimo de Melchor García y Beatriz Bueno, y quedó huérfano a tierna edad. Beatriz contraería luego matrimonio con Julián Vargas (Vargas 1956: 158).

10 "Los curas de provincias generalmente eran buenos quechuistas. Un párroco de Urubamba llegó a escribir obras teatrales. En las provincias se podía encontrar predicadores en quechua... El clero utilizaba el quechua con un sentido práctico, para la prédica, mientras los civiles lo cultivaban como una afición erudita..." (Valcárcel 1981: 69-70). 
Un protagonista de la renovación de la Iglesia en Cusco fue el obispo Pedro Pascual Farfán de los Godos (1870-1945) ${ }^{11}$. Nacido en una tradicional familia cusqueña, fue también uno de los personajes más influyentes de la Iglesia católica en el país y reconocido representante del indigenismo eclesiástico peruano. Fue obispo de Huaraz (1907-1918) y de su natal Cusco (1918-1933), y luego arzobispo de Lima (1933-1945).

El obispo Farfán se identificó profundamente con la historia y los problemas sociales de su tierra natal y emprendió una intensa labor pastoral, intelectual y social en esta área. Así, realizó exhaustivas visitas pastorales, convocó dos sínodos diocesanos en Cusco, fue el promotor del Congreso Interdiocesano de Acción Social y presidió el Patronato de la Raza Indígena (PRI) del Cusco. Su posición en el debate sobre la cuestión indígena se encuentra plasmada en sus cartas pastorales e intervenciones en eventos eclesiales y seculares. Además de sus escritos en quechua (Farfán 1918), destacó su Exhortación pastoral sobre la protección de la raza indígena. En este documento Farfán señala que la gran obra nacional del día era el de la protección y el resurgimiento de la raza indígena (Farfán 1920: 4). Al mismo tiempo, analizó detalladamente los problemas de propiedad en el mundo rural (Farfán 1920: 5-11).

Valcárcel, además de Isaías Vargas y del obispo Farfán -a

160 quien calificaba como "hombre muy inteligente que destacó como protector de los indios"-, mencionaba a algunos notables eclesiásticos de su época. En primer lugar, al monseñor Juan Falcón, obispo de Cusco entre 1893 y 1909. También

11 Hasta el momento, el estudio más completo sobre Farfán es el de Vega-Centeno (1993) [no está en las referencias]; véase también Klaiber (1988: 263-268). 
recordaba a varios canónigos, especialmente a Hernando Vega-Centeno, sobrino del obispo Farfán; Juan Francisco Palomino, párroco de San Blas y experto quechuista ${ }^{12}$; José Benigno Espinoza, "fanático pierolista" y "director de una de las primeras academias de quechua fundadas en el Cusco"; Mariano Rodríguez, "famoso quechuista, escribió varios dramas en ese idioma que llegaron a ser representados en el Cusco"; Mariano N. García Bueno, "que fue diputado y medio hermano de Isaías Vargas"13, y a Fernando Pacheco "el primero en componer una Historia del Cusco" (Valcárcel 1981: 68-69).

\section{El canónigo Isaías Vargas: breve nota biográfica ${ }^{14}$}

A lo largo de su vida Isaías Vargas se destacó como sacerdote, educador, periodista, intelectual y por su participación cívica

12 "Sin serlo, Palomino tenía toda la apariencia de un indio y dominaba muy bien el quechua, tanto verbal como gramaticalmente, a tal punto que cuando años después Paul Rivet realizaba su monumental bibliografía del quechua lo puse en contacto con el cura, porque podía serle un eficiente informante". Valcárcel señalaba que Palomino "era el más beligerante, algunos de sus sermones en quechua tenían un carácter revolucionario contra los blancos, por lo que era temido. En lo referente a su obra, no sólo hizo trabajos lingüísticos, sino que también escribió breviarios de oraciones en quechua" (Valcárcel 1981: 68-69).

13 Mariano N. García Bueno nació en el pueblo de Huaro en 1861. Como ya se ha mencionado, fue medio hermano de Isaías Vargas. Fue un destacado párroco y canónigo en Cusco y diputado de la República por las provincias de Canas y Espinar entre 1919 y 1930. Participó activamente en el Círculo de Obreros Católicos del Cusco y en otras organizaciones sociales, pastorales y culturales. Para analizar algunas de sus ideas sociales véase García (1914).

14 La mayor parte de los datos de esta sección de la breve autobiografía de monseñor Vargas han sido recogidos de Vargas (1956:164-169). Lamen- 
en algunas instituciones públicas. Nació en Yauri, capital de la provincia cusqueña de Espinar el 5 de julio de 1876, siendo hijo de Julián Vargas y Beatriz Bueno. Ingresó al Seminario San Antonio Abad de Cusco en 1894 donde, al culminar sus estudios, fue distinguido con la medalla de oro por sus méritos académicos. Recibió la ordenación sacerdotal en 1901 de manos del obispo de la ciudad, monseñor Juan Antonio Falcón.

Su labor pastoral fue muy amplia y reconocida ${ }^{15}$. Fue párroco de varias circunscripciones, formó parte del cabildo catedralicio de Cusco desde 1910, director espiritual de numerosas asociaciones pías, capellán de varias instituciones y visitador de congregaciones religiosas. Asimismo, los obispos de la ciudad le confiaron un conjunto de cargos de responsabilidad a nivel diocesano.

Respecto a su participación en instituciones públicas, destacó como miembro del Consejo Provincial de Cusco (19051911) y ejerció la alcaldía de la ciudad de manera provisoria en 1909. Fue socio de la Sociedad de la Beneficencia Pública (1948) y presidente de la misma en 1951. También participó en instituciones culturales y fue socio del Ateneo Incaico (1930) y de la Academia de la Lengua Quechua (1953). En cuanto a su labor periodística, fundó el diario La Unión, del cual fue director entre 1904 y 1910; también fue director del Boletin Eclesiástico (1912) y del diario La Restauración (1911).

tablemente, no he encontrado información sobre la fecha de fallecimiento del ilustre canónigo.

15 Por ejemplo, en 1928, una publicación periódica madrileña resaltaba sus cualidades oratorias, su amplia cultura, y sus méritos en el desarrollo de su labor sacerdotal. Allí se hacía referencia a su nombramiento para el puesto de magistral de la Catedral de Cusco (Panorama 1928: 4-5). 
Asimismo, fue redactor en numerosos diarios cusqueños y colaboró con la revista El Perú Indigenista con sede en Lima.

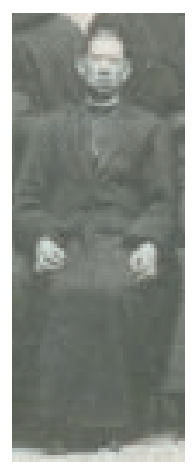

Monseñor Isaías Vargas en $1926^{16}$

Publicó 27 obras, muchas de ellas dedicadas a la cuestión indígen $a^{17}$. Otros de los temas recurrentes de sus libros fueron los espirituales-devocionales; escribió catecismos, textos escolares de psicología, filosofía, lógica, moral y religión, y una monografía sobre la basílica catedral de Cusco.

Asimismo, tuvo una amplia trayectoria como educador, habiendo sido profesor en el Colegio Nacional de Educandas, en el Colegio Nacional de Ciencias, en el Seminario de San Anto-

16 Fragmento de la fotografía de los miembros del Patronato de la Raza Indígena de Cusco en 1926. Tomado de Vega-Centeno 1993: 99.

17 Mi interés por este asunto surgió cuando, investigando en la Biblioteca Nacional del Perú, me encontré con las publicaciones de monseñor Vargas respecto al problema indígena. Algunas de sus obras recopilan sus artículos desde que fue redactor del periódico católico cusqueño $L a$ Unión en 1904 hasta su madurez durante la década de1950. Sus estudios más importantes se encuentran en la bibliografía que se presenta al final de este artículo, los que fueron consultados para la redacción de este texto. 
nio Abad y en varios colegios religiosos del Cusco. El espectro de materias que enseñó fue muy amplio e incluyó cursos de matemáticas, ciencias, filosofía, teología, sociología y francés.

Como se ha mencionado, monseñor Vargas es recordado como un eficaz colaborador del obispo Farfán en la diócesis de Cusco (1919-1933) y se convirtió prontamente en uno de sus hombres de confianza. Así, a los pocos meses de su instalación en la ciudad, el prelado nombró a Vargas como canciller del obispado (noviembre de 1918) y luego, en 1923 , pro-vicario general, y le encargó la administración de la diócesis (Vargas 1956: 165).

Además de participar con el obispo en diversas labores pastorales y de gobierno eclesial, Vargas fue especialmente diligente en los temas sociales relacionados con el problema indígena. Por ejemplo, el canónigo fue el presidente de la Comisión Organizadora del mencionado Congreso Interdiocesano de Acción Social. Este evento se celebró en Cusco en mayo de 1921, con delegados de Cusco, Arequipa, Ayacucho y Puno. Dichas diócesis concentraban una alta proporción de la población indígena peruana, así como uno de los niveles más altos de pobreza.

Estas zonas, desde fines del siglo XIX se habían visto afectadas por levantamientos campesinos como reacción a los abusos cometidos por hacendados y autoridades locales, y por la progresiva expansión de las empresas dedicadas al comercio internacional de lanas a costa de las tierras comunales. En muchos casos, la represión gubernamental de estos movimientos alcanzó un alto grado de violencia (Larson 2004: 173-174). En este sentido, la reflexión sobre la cuestión indígena se convirtió en un tema principal e ineludible 
del congreso. Hubo un énfasis en los problemas económicos de los indios y se analizó el proceso de expansión de las haciendas en detrimento de las comunidades campesinas. Se analizaron detalladamente las condiciones de salubridad, la mortalidad infantil, los problemas generados por el alcoholismo, las falencias de la educación pública y los vacíos dn la formación religiosa en las poblaciones de la región.

En esa línea, monseñor Vargas sostenía que las raíces del problema indígena y de los recientes levantamientos en la región estaban estrechamente vinculadas al régimen económico imperante y a los problemas de propiedad. Para graficar esto, narraba las vicisitudes de las comunidades de Canas y Espinar en el departamento de Cusco, que habían sido despojadas de sus tierras por la gran hacienda y los gamonales a través del fraude, el engaño o la fuerza. Según Vargas, el problema racial no se solucionaría si no se hacía justicia a los afectados en sus derechos de propiedad y, por el contrario, los indios serían fácilmente seducidos por las propuestas violentistas de los bolcheviques.

Así, Vargas exhortaba a los participantes del congreso a que se elevara una solicitud a las cámaras legislativas para sancionar una ley que garantizara debidamente las propiedades agrarias de las comunidades rurales y promover la formación de patronatos y sindicatos de indios, que bajo la protección del gobierno, reivindicaran por la vía legal los terrenos usurpados por los gamonales (Vargas 1922: 346-348). Las conclusiones del congreso incluyeron ambas propuestas, las que fueron gestionadas en el parlamento nacional por el sacerdote cusqueño Mariano García, quien era a su vez diputado de la República. 
Monseñor Vargas también colaboró con el obispo Farfán en el Consejo Provincial del Patronato de la Raza Indígena (PRI) de Cusco, una institución estatal creada por el gobierno de Augusto B. Leguía en 1922. Su objetivo era investigar las causas de los disturbios indígenas en el país, amparar sus derechos de propiedad, estimular las actividades laborales y atender las quejas y reclamos indígenas ${ }^{18}$. Muchas de las reflexiones de sus obras tuvieron como base su experiencia en esta institución.

Durante los últimos años de su vida, la labor de Isaías Vargas fue ampliamente reconocida por autoridades civiles y eclesiásticas. Así, en 1951 y en 1952 recibió cablegramas del cardenal Giovanni Battista Montini, secretario sustituto de estado de la Santa Sede (y quien años después se convertiría en el papa Pablo VI), felicitándolo por sus cincuenta años de sacerdocio, los que se celebraron con una misa a la que asistieron representantes del gobierno y de la Iglesia, así como varias generaciones de sus antiguos alumnos (Vargas 1956: 169).

18 Los miembros de esta institución eran elegidos por dos años que podían ser renovados continuamente. Debido a la falta de presencia del Estado en extensas zonas del país y a la influencia de la Iglesia en el mundo rural, el gobierno optó por delegar los cargos más importantes del PRI en los obispos. Las atribuciones de esta institución fueron considerables, pues tenía la capacidad de presentar al gobierno proyectos de ley de carácter nacional y regional, gestionar ante los poderes públicos los reclamos judiciales de los indígenas y emitir los informes que le eran pedidos al gobierno sobre los asuntos relativos a los fines de esta entidad (Boletín del Ministerio de Fomento. Sección de Asuntos Indigenas 1926: 26-27). 


\section{Los Apuntes criticos sobre asuntos indigenistas (1946) y las Recopilaciones (1948)}

La obra Apuntes críticos sobre asuntos indigenistas (1946) es una compilación compuesta por un prólogo y once ensayos. De ellos, seis tratan temas históricos y etnológicos ("Cosmogonía i Antropogenia Incaicas"19, "Los mitos sobre el Origen del Tahuantinsuyo", "La Economía Política del Incanato", "El pretendido comunismo del Incanato", "La Filosofía i las Ciencias en el Incanato", "La factura de la arquitectura peruana precolombina"), tres son estudios lingüísticos sobre el quechua ("La Etimología del nombre Cuzco i la primera i la segunda fundaciones de esta Ciudad i de los imperios prehispánicos", "Algunas particularidades del queshua", e "Inti-Raymi, o InticOraynin, o mejor Intic-Ttijraynin"), y dos se enfocan en temas sociales ("La psicología del Indio" y "La Instrucción, la alfabetización i educación del futuro indio").

En 1948, dos años después de la publicación de sus Apuntes, monseñor Vargas publicó sus Recopilaciones psico-sociológicas de mis apuntes críticos sobre asuntos indigenistas. Se trataba de un estudio más sistemático que el anterior y conformaba un conjunto de propuestas para el Segundo Congreso Indigenista Interamericano que se celebraría en Cusco entre el 24 de junio y el 4 de julio de 1949.

La mayor parte de estos escritos se habían publicado previamente en diversas revistas y periódicos. Allí se recogieron algunas de sus principales reflexiones sobre el mundo

19 Como señala Vega-Centeno: "La ortografía de Mons. Vargas (no usa la " $y$ " griega) tiene que ver con los debates sobre el español en uso en los Andes, liderados en los años 30 del s. XX por el Dr. José Gabriel Cosio" (Vega-Centeno 2013: 270). 
indígena peruano desarrolladas a lo largo de más de cuatro décadas. Considerando que varias de las ideas contenidas en los ensayos se repiten, en el presente trabajo se ha optado por analizar las líneas temáticas presentes en ambas obras.

\section{La doctrina social de la Iglesia, la "auténtica democra- cia" y los sistemas totalitarios}

Antes de desarrollar el tema propiamente indígena, Vargas expuso sus posiciones filosóficas y buscó definir algunos conceptos que consideraba fundamentales. Así, en el prólogo de Apuntes críticos sobre asuntos indigenistas enmarcaba sus escritos dentro de las líneas de la doctrina social de la Iglesia católica (DSI). Siguiendo las enseñanzas del papa Pío XII, se declaraba partidario de una "auténtica democracia, la democracia cristiana”. Una característica indispensable de este sistema era la centralidad de la persona humana, la cuál debía ser "agente, fundamento y fin" de la sociedad y del Estado (Vargas 1946: 3).

Para el canónigo, la antítesis de un estado democrático era uno dejado al arbitrio de las masas. Las instituciones políticas debían ejercer su poder con autoridad verdadera y efectiva para cumplir con su misión y los seres humanos debían reconocer su dependencia frente a alguna autoridad superior. Más aún,

168 siguiendo los principios básicos de la filosofía católica, sostenía que el Estado y las leyes debían estar sustentadas en un derecho natural que tuviera sus fundamentos últimos en Dios. En ese sentido, si la autoridad política desconocía esta realidad con leyes atentatorias contra la dignidad humana, "seguirá el peligro de que el egoísmo del dominio o de los intereses prevalezca sobre las exigencias esenciales de la moral política y social, y de que las vanas apariencias de una democracia de 
pura fórmula sirvan no pocas veces para enmascarar lo que es, en realidad, lo menos democrático" (Vargas 1946: 8). Asimismo, mostraba una visión crítica frente a los totalitarismos de su época al condenar a los Estados que conducían políticas de masificación y manipulación social: "La masa es la enemiga capital de la verdadera democracia y de su ideal de igualdad y libertad". Para evitar este mal era necesario formar la conciencia ciudadana de los habitantes respecto a su dignidad, su libertad, sus deberes y derechos. También consideraba nocivos los igualitarismos radicales, pues la desigualdad tenía su origen en "la naturaleza misma de las cosas" y "lejos de lesionar en manera alguna la igualdad civil, le dan su significado legítimo, es decir, que ante el Estado cada uno tiene el derecho de vivir honradamente su existencia personal, en el puesto y las condiciones en que los designios y la disposición de la Providencia lo han colocado" (Vargas 1946: 7). Esto no significaba que estuviera en contra de los cambios políticos o que apoyara un inmovilismo social de carácter providencialista. Más bien, estas afirmaciones eran una crítica tanto a los fascismos como a los proyectos marxistas y socialistas en boga. Según el autor, los enemigos de la libertad eran las "ideas patológicas" sobre las cuáles se edificaron los regímenes totalitarios. Dos ejemplos de ellas son las ideologías racistas (nazismo y fascismo) y clasistas (marxismo).

A lo dicho, agregaba una censura contra los proyectos estatistas:

[...] es un error gravísimo tanto en ética, como en sociología, pretender hacer derivar todos los derechos de los poderes del Estado, el individuo i la familia son anteriores al Estado con todos sus derechos emanados de la ley natural o moral, i el estado no puede aniquilarlos, sino garantizarlos... El hacer derivar todo derecho del Estado es una tesis 
que se halla en abierta oposición con nuestra tan decantada democracia, i admitirla sería abrir puerta franca al totalitarismo, a la tiranía, que van camino a la Estatolatría (Vargas 1946: 125).

Sin embargo, siguiendo a León XIII y la encíclica Quadragesimo anno de Pío XI, también condenaba al liberalismo económico por haber producido una profunda división entre ricos y pobres, entre burgueses y proletarios y por propugnar:

[...] el enriquecimiento individual, sin limitación, de la propiedad privada así como su adquisición de cualquier manera. Su fórmula es muy conocida: "Laissez faire, laissez passer", la que traducen así: "Enriqueceos sin medida". De esta manera que en este sistema económico caben la bolsa negra, el mercado negro i el salario negro o en términos más claros, las raterías, usuras i latrocinios: las injusticias (Vargas 1948: 31).

\section{El APRA y los partidos políticos del Perú}

A pesar de su abierto rechazo contra los movimientos revolucionarios, Vargas expresó su afinidad hacia los de carácter reformista. Así, en una entrevista que le hicieron en 1946 señalaba que en el pasado había sido simpatizante del Partido Civil, del Demócrata, de la Unión Cívica y del Democrático Reformista de Leguía, porque "han hecho mucho, en medio

170 de sus errores, por el bien del país”. Fue crítico del Partido Constitucional "porque el dominio mediante el sable i la espada era dictatorial y contrario a mis tendencias". Tampoco le agradaba el Partido Liberal, el cual había sido "objeto de mi detestación" debido a que: "presentaba la caricatura de la libertad, la igualdad, la fraternidad y representaba el individualismo económico que ha labrado la división de las clases sociales, entre ricos i pobres". Respecto al comunismo afir- 
maba: "lo abomino, lo detesto, siento asco por sus teorías" (Vargas 1947:331).

Cuando le preguntaron acerca de su posición frente al APRA, declaró que si bien no estaba inscrito en ningún partido político: "sí tengo simpatías por el Partido del Pueblo más que por cualquier otro". Entre las razones que daba para sustentar esta cercanía señalaba que varios puntos del programa político-social aprista "se hallaban en armonía con las enseñanzas de los Papas en materias sociales", también alababa "la entereza, franqueza y gallardía con que el APRA combate a ese monstruo de errores e inmoralidades que se llama comunismo o marxismo i también los demás socialismos" y destacaba que el APRA, desde que estaba en el poder, había dejado de lado su veta antirreligiosa (Vargas 1947: 330). Esta simpatía no fue óbice para que criticara el postulado aprista del espacio-tiempo-histórico, tal como había sido desarrollado por Antenor Orrego: "Le aconsejaría a mi amigo muy distinguido, admirado sr. Raúl Haya de la Torre, a que abandonara esa posición que le perjudica, i estudiase la filosofía realista moderada o intelectualista, tanto más cuando que la llamada filosofía del APRA en nada influye sobre la moral, la democracia i demás postulados que hace profesión dicho partido" (Vargas 1947: 338-339).

La opresión estatal, económica y social como causas de la "degradación" del indio

En los ensayos referentes a temas históricos, monseñor Vargas buscó interpretar las causas del estado de marginación de la población indígena de su época. Así, en Economía politica del incanato. Causas de la degeneración del indio. Su regeneración criticaba la idealización del Tahuantinsuyo por 
parte de numerosos estudiosos de su época. En contraste con ello, sostenía que durante el incanato el indio estuvo oprimido por el Estado y que las comunidades indígenas enemigas fueron reprimidas ferozmente. Aprovechando esta reflexión para criticar explícitamente a los totalitarismos nazi, fascista y soviético, afirmaba anacrónicamente, que "el incanato no ha sido más que una de las variantes de estos socialismos" y que la consecuencia de este totalitarismo había sido la degeneración del indio (Vargas 1946: 50-51). El sustento académico de esta afirmación era débil, pero era un criterio que tenía cierta difusión entre los intelectuales peruanos contemporáneos ${ }^{20}$.

Según Vargas, una de las razones de la "degeneración" de la raza indígena había sido la opresión estatal y social, la cual había estado presente desde el incanato y se había prolongado por tres siglos con el régimen español a pesar de los esfuerzos de la Iglesia católica por mitigar esta realidad. La condición de los naturales no mejoró sustantivamente con el advenimiento de la República. Es decir, durante el incanato los indígenas habían tenido que servir con "onerosos trabajos i otras contribuciones" al Estado inca. Luego pasaron de la tiranía inca a la propia de los "mineros i encomenderos españoles”. Después de la emancipación, los aborígenes tendrían una "situación análoga de humillación i abatimiento

20 Francisco García Calderón en El Perú contemporáneo sostenía, respecto al sistema de gobierno inca, que "jamás maquinaria más universal e inflexible destruyó tan perfectamente todo individualismo" creando "un singular Imperio, en el que dominaba el más despótico y paternal de los socialismos". Ello generó "una raza tenaz y servil, obediente y paciente, sin individualidad ni espíritu de insurrección. Se enriqueció el automatismo, el subconsciente de los pueblos, destruyendo todo sentimiento del yo" (García Calderón 2001: 78-79). 
bajo la servidumbre de los gamonales blancos o mestizos, quienes han continuado i aún continúan explotándoles, no obstante que han transcurrido más de un siglo de haberse proclamado i legislado la igualdad republicana" (1946: 51).

Siglos de explotación habían formado "un hábito, una segunda naturaleza" en el indio, lo que había llevado a que este "nazca paria, viva paria y muera paria" y habían producido arraigados "complejos sicopatológicos" en los pueblos andinos. Esta situación era el resultado de la injusticia contra el indio. A pesar de que durante el virreinato hubo leyes favorables a los naturales y que las constituciones del Perú republicano habían declarado la igualdad de los habitantes del país, ha habido una incoherencia entre el país legal y el país real:

Los indios han continuado en el mismo estado, sin garantía para el ejercicio de buen número de sus derechos; la igualdad ha sido un mito; los unos, algunos blancos i mestizos, han tenido parece garantías para la impunidad de sus delitos i para tener en dura servidumbre a los indios; ha continuado la diferencia de clases i raza i de castas, i parece que ciertas autoridades i aún magistrados han sido colocados como protectores de los que visten casimir i gastan cuellos planchados, pero para continuar oprimiendo y tiranizando al indio. Las leyes constitucionales i otras disposiciones legales no han sido más que una irrisión, tratándose del indio" (Vargas 1946: 53-54).

En esta línea, sobre la base de su experiencia en el Patronato de la Raza Indígena durante el gobierno de Augusto B. Leguía, criticaba duramente el sistema de explotación aún vigente. En concreto, reprobaba la acción de los magistrados en las zonas rurales, los cuáles eran corrompidos fácilmente por los gamonales y hacendados locales en desmedro de los derechos y las tierras de las comunidades campesinas: 
[...] consta a los lectores las maneras cómo ciertas personas de unas pequeñas parcelas de tierra han formado buenas haciendas, i cómo en tierras que eran de alguna comunidad indígena han aparecido grandes haciendas, viéndose obligados los indios comuneros o a emigrar a otros lugares o a convertirse resignados en colonos del que se había erigido, mediante qué leguleyadas o qué embustes, en propietario indiscutible del ayllo. Amén de otras raterías i otras expoliaciones de otros bienes, las que no llegan a tener su reparación. Estos hechos delictuosos no se ocultan a la observación del mismo indio que suele decir con frecuencia este satírico apotegma: "Mutte ccarallanmanta miste sayarin". Cuya traducción es la siguiente: "De la cáscara de un grano de maíz sancochado se levanta i enriquece el mestizo" (Vargas 1946: 59).

Monseñor Vargas sostenía que los sacerdotes tenían el deber ineludible de denunciar las injusticias que veían en el país y desarrollar un espíritu de cooperación nacional para aliviar los problemas del indio. Hacía un recuento de las ocasiones en las cuáles la jerarquía de la Iglesia había intervenido en favor de los indios americanos. Incluía el magisterio de diversos papas como Pablo III, León XIII, Benedicto XIV y, más recientemente, Pío X. En el caso específicamente peruano, mencionaba las disposiciones del arzobispo de Lima Pedro García Naranjo y del VII Concilio Provincial Limense (1912) y las de monseñor Pedro Farfán de los Godos y el V Sínodo Diocesano del Cusco (Vargas 1946: 84-86).

Siguiendo esta línea de defensa eclesial del indio, Vargas se oponía tajantemente a las tesis sobre la inferioridad racial del indio. Sin embargo, al margen de la acción del Estado y de los grupos dominantes, afirmaba que había algunas limitaciones de carácter cultural que contribuían a su "degradación” y que eran difíciles de desarraigar. Dos de las más nocivas eran la falta de aspiraciones y la cocainomanía. Sobre lo primero, 
volvía al punto de que si bien el régimen comunitario le había servido al indio para proteger sus tierras frente al avance del latifundismo blanco y mestizo, le había privado de iniciativa individual y había cercenado su capacidad de superación (Vargas 1946: 88). En cuanto a lo segundo, planteaba que el uso habitual de la coca "no se puede dudar que contribuye al embrutecimiento del indio". Después de explicar en detalle los efectos fisiológicos de la mascadura de coca concluía que: "atenuar el uso de la coca en la raza aborigen hasta conseguir su completa extinción, con la educación, sería una defensa a su mentalidad normal i sería un medio para robustecer i fortalecer su organismo" (Vargas 1946: 88).

\section{La crítica a Mariátegui}

En su ensayo El pretendido comunismo del incanato criticó algunas de las posiciones difundidas por los marxistas peruanos. Después de definir al comunismo como un sistema colectivista que propugnaba la supresión de la propiedad privada, la familia y otras instituciones, señalaba que era erróneo sostener que el imperio inca hubiera adoptado este sistema. En primer lugar, porque el comunismo era un sistema imposible en el terreno de los hechos. El Tahuantinsuyo tampoco fue un régimen socialista, por lo menos no un socialismo moderno. En todo caso, habría sido un socialismo "teocrático" e "idólatra", donde la pequeña propiedad privada estuvo reconocida por la ley consuetudinaria (Vargas 1946: 101).

Sin embargo, Vargas consideraba que el sentido comunitario persistente en el mundo indígena de su época no tenía su origen en el ayllu incaico, sino en los tiempos de la creación de las reducciones por el virrey Francisco de Toledo durante la segunda mitad del siglo XVI. Allí, se estableció un sistema 
de organización social y administrativo aún vigente en las serranías peruanas. Por ejemplo, los varayoc o envarados, con los títulos de alcaldes y regidores eran cargos coloniales y no prehispánicos.

Sobre la base de estas reflexiones cuestionaba el verdadero significado del lema de José Carlos Mariátegui "Peruanos, peruanicemos el Perú". Se preguntaba si lo que en realidad proponía era un regreso al incario o la imposición de un régimen comunista criollo. Para Vargas, ninguna de las dos situaciones era deseable pues con la primera (el incario), la imperfecta democracia peruana retrocedería para convertirse en un totalitarismo teocrático y los peruanos se convertirían en "esclavos o semi-esclavos de un señor, denominado ficticiamente hijo del dios Sol", regresarían al politeísmo idólatra y fetichista, y la familia y la libertad individual serían absorbidas por una maquinaria estatal. En el segundo caso (el comunismo), "ya no cabría que el peruano se peruanice, puesto que el Incario no fue comunista, sino más bien sería sovieticemos el Perú", o en otras palabras, que se extirpe la tradición histórica peruana incaica, colonial y republicana, para imponer un modelo externo (1946: 107-108).

Así, peruanizar al Perú no debía significar rusificarlo como pretendían los comunistas. Para Vargas, el marxismo no era científico, sino una ideología materialista y atea, con una errada interpretación de los procesos históricos, y el germen de uno de los peores totalitarismos políticos. Advertía que un verdadero católico nunca puede aceptar las ideas del comunismo y mucho menos militar políticamente en un partido marxista. Paralelamente, negaba tajantemente que esta condena significara una despreocupación por las clases populares. En contraposición, alababa abiertamente al "gran 
escritor Raúl Haya de la Torre que racional i sinceramente es antiimperialista, anticomunista $i$ anti totalitarista $i$ partidario de una verdadera democracia" (1946: 109).

\section{Tres reformas claves: políticas educativas, el régimen de propiedad y el sistema de justicia}

La "regeneración del indio" y su "incorporación a la cultura nacional" requerían acciones de largo plazo. Era necesario superar el desorden institucional del país, el caudillismo y los cambios abruptos de gobierno que, hasta el momento, habían impedido dar continuidad a las políticas favorables para el indígena peruano. De manera especial, resaltaba tres aspectos que necesariamente debían abordados por el Estado y los sectores dirigentes: las políticas educativas, el régimen de propiedad de las comunidades campesinas y la reforma del sistema de justicia.

Respecto al primer punto, señalaba que en el mundo rural peruano era evidente la falta de escuelas y medios de culturización. Sostenía que había tres tipos de escuelas: la liberal, la comunista y la cristiana. La primera, predominó durante las cinco primeras décadas de vida independiente y formó a las élites peruanas. La educación moral de ellas fue mínima y "no se hizo nada más que preparar generaciones de gamonales que en los pueblos i pagos iban a continuar con la opresión de los indios" y generaciones de funcionarios públicos que "rebajarían con sus injusticias i depredaciones los grados del termómetro de la cultura social". Asimismo, también mantenía que la escuela "comunista" era atea, nefasta y "solo transformaría al indio de ser un paria analfabeto a ser un paria alfabeto" (Vargas 1946: 65). 
Como parece obvio, después de estas generalizaciones, para Vargas la escuela cristiana era la opción necesaria para el mundo andino e hizo una extensa apología de la misma. La Iglesia y los sacerdotes, "en medio del abandono de los poderes civiles" habían acompañado al indio durante el Virreinato y la República, creando escuelas, evangelizando, dándole compañía, consuelo espiritual y defendiendo sus derechos. “[...] él [el sacerdote] quien se le ha aproximado más que nadie, hablándole de sus deberes i derechos en su propio idioma, el queshua... [...] él quien con la docencia de este Evangelio ha mitigado los ímpetus e instintos del abusivo gamonal; él quien, como justiciero árbitro, ha solucionado los litigios que tenían entre sí los indios" (Vargas 1946: 70). Recordaba algunos casos concretos de sacerdotes promotores de escuelas rurales en la serranía peruana y también a otros que lucharon contra las irregularidades en las políticas de enganche y contra las invasiones de tierras de las comunidades.

Respecto a los medios para llevar adelante una política educativa eficaz, planteaba que el indio debía ser instruido en su propio idioma: "porque, repetimos, al indio no se le puede hacer pensar en castellano", debido a que la mayor parte de las personas razonan en su idioma nativo:

A la observación de estos i otros hechos, que mejor los palparán los maestros de provincias, no hay más conclusión para la práctica: que al indio hay que instruirle en su idioma nativo. I en confirmación de esto, una vez que hablábamos con una maestra de un pueblo aún cercano al Cuzco, teniendo en la mano una cartilla de Catecismo Kheswa, nos decía: Ésta cartilla, cuando se les lee i se les explica en kheswa, con qué alegría i facilidad asimilan mis alumnas (Vargas 1946: 275). 
Pese a los esfuerzos de los maestros de primaria, las campañas pasadas de alfabetización no habían fructificado por la falta de un sistema adecuado a la fonética de los quechuahablantes. Para su instrucción futura, proponía que la educación elemental de los primeros años debía ser mayoritariamente en quechua y que luego el castellano se fuera incorporando en los cursos.

Consideraba que la formación moral, enraizada en las tradiciones andinas, tanto incaicas como cristianas, debía ser parte indispensable de la educación. Había que inculcar en los indios los principios del incanato: "Ama wua, ama iyolla, ama k'illa". Para ello, el maestro rural debía crear hábitos en los alumnos. Uno de los medios era que las escuelas tuvieran pequeños campos de cultivo de cereales, en donde los niños pudieran educarse en el trabajo. También habituar al niño indio en el aseo, a bañarse todos los días, a crear hábitos de ahorro, enseñar a las niñas a hilar. A la par, el indio debía recibir una sólida instrucción religiosa, para interiorizar los principios cristianos y para depurar su fe de "toda superchería". Esta formación religiosa y moral, tendría también una función cívica pues convertiría al indio en:

$[\ldots]$ un hombre consciente de la dignidad de la persona humana, que debe respetar en sí mismo i en los demás i hacerla respetar, i de los derechos que se derivan de esta alta dignidad, como el de la libertad - no licencia; a que en armonía con esta dignidad se procure una posesión económica holgada, semejante a la de los demás civilizados, mediante el trabajo honrado i el ahorro; $i$ a que siga practicando el cooperacionismo fraternal no sólo con los de su raza sino con todos los que forman la sociedad peruana. De esta manera conspiraremos del modo más eficaz posible a que sea una realidad aquella bella acotación de nuestra Carta Fundamental: "El Perú es república democrática" (Vargas 1946: 287). 
También consideraba central la educación de las clases terratenientes. Los gamonales eran descritos como una "gran plaga social", de "degenerados i degeneradores" que maleaban a los indios. Además de endurecer las sanciones legales contra sus abusos, era necesaria su formación moral: "[...] hay que educar con cuidado i esmero a esos parásitos, a quienes llamamos gamonales, por medios más eficaces que los del Incanato, a que no sean "mentirosos, ni farsantes, ni ladrones, ni rateros, ni ociosos" (Vargas 1946: 284).

Sobre la educación superior, proponía que la universidad, con el apoyo del Estado, debía cumplir un papel esencial en el estudio de la cultura indígena a través de la creación de cátedras de folclore, arqueología, academias de quechua, entre otras iniciativas. Alababa algunas iniciativas en curso como eran la Revista Universitaria del Cusco, por sus competentes estudios de la realidad indígena y la obra del Instituto de Paidología Andina, creado el 21 de enero de 1945.

Respecto al régimen de propiedad, Vargas sostenía que había tres tipos de indios: a) el que tenía una pequeña propiedad agraria o una estancia de regular extensión; b) el propietario comunero, y c) el que no poseía propiedad alguna. Consideraba positivo y necesario que la Constitución de 1933 hubiera protegido la propiedad indígena comunitaria

180 declarándola intransferible, imprescriptible e inalienable, pues así se protegía las tierras campesinas frente al peligro de ser absorbidas por los grandes latifundios. Sin embargo, el autor consideraba que era necesario promover la propiedad privada agraria del indígena y no solo la comunitaria. Para ello, el Estado debía crear leyes que protegieran este tipo de propiedad, que regularan las relaciones del patrono con el colono (para romper con el régimen agrario co- 
lonial) y que se parcelaran los bienes de las comunidades entre los mismos indios que componen el ayllu. Asimismo, estimaba conveniente que se expropiaran algunos latifundios, "especialmente de los que se han formado a expensas del despojo de bienes de indios, para parcelarlos entre los indios que necesitan" (1946: 74).

Estas ideas las había defendido públicamente mucho tiempo atrás. En su ensayo Los bienes de las comunidades indigenas publicado en El Comercio de Cusco (9 de diciembre 1924) comentaba el artículo 41 de la constitución de 1920. Allí, alababa el hecho de que por primera vez en la historia republicana se hubiera dado protección legal a las comunidades indígenas y a sus bienes. En dicha disposición legal se declaraba la imprescriptibilidad de las tierras comunitarias, las cuales solo podían transferirse en casos especiales. Vargas evaluaba las ventajas y desventajas de esta norma. Ella era beneficiosa en cuanto protegía las tierras comunitarias frente a "la rapacidad del gamonal, además abre la posibilidad que algunos bienes rurales arrebatados en el pasado por fraude sean devueltos a sus legítimos dueños" y libraba al indio del pauperismo, "aunque en razón de no tener más aspiración que llenar la troje para sólo el consumo del año, i de la miseria, i finalmente procurar el abaratamiento de los artículos de primera necesidad". Sin embargo, la imprescriptibilidad traería consigo algunos problemas en el orden económico y social. Vargas creía que era necesario que el indio tuviera acceso a la propiedad privada para incentivar su progreso material. Consideraba que la producción de las tierras comunitarias tendía a ser menor que la individual: "cuando el indio tiene tierras privadas, ellas están mejor cultivadas que cuando son comunitarias". En el orden social, el régimen comunitario debilitaba "el derecho natural que tiene el indi- 
viduo a la propiedad privada, i como los derechos en la vida del hombre están íntimamente ligados uno del otro, el desmedro del derecho de propiedad y máxime su pérdida trae como consecuencia la disminución de otros derechos y por ende de la dignidad humana". Las experiencias colectivistas, empezando por los falansterios rurales de Fourier habían sido un fracaso económico.

En este sentido, Vargas consideraba que en vez del régimen comunitario concedido a los indios, era más provechoso para ellos y para el país dividir las tierras comunitarias en parcelas y distribuirlas como propiedad individual. Sugería que si las tierras comunitarias eran insuficientes, debía procederse a expropiar algunos latifundios, especialmente cuando las tierras de estos no habían sido trabajadas (Vargas 1953: 296-297).

Un tercer aspecto era el relativo a la reforma y moralización del poder judicial. Denunciaba que la concusión y el prevaricato eran delitos ampliamente difundidos y muy raras veces sancionados. Graficaba esta realidad exponiendo una serie de hechos concretos de abusos de autoridad y de corrupción, especialmente por parte de los gamonales, quienes habían copado puestos importantes en la administración de justicia en las regiones. Criticaba el hecho de que se hubiera debilitado a los juzgados comunes y que, más bien, las auto-

182 ridades políticas estuvieran ejerciendo funciones de justicia, pues estas eran más propensas a los sobornos.

Para enfrentar este problema proponía la elaboración de una nueva ley orgánica del poder judicial que impusiera sanciones más expeditas y efectivas, hacer que el Ministerio Fiscal Supremo de la República se encargara directamente de estos delitos, y establecer mecanismos para una selección de ma- 
gistrados caracterizados por su entereza moral, instrucción e independencia política.

\section{Reflexiones finales}

Vargas fue un conocedor de la historia de su Cusco natal, un reconocido estudioso del idioma y de la cultura quechua, un diligente miembro del Patronato de la Raza Indígena durante la década de 1920 y un estrecho colaborador del obispo Pedro Farfán. Su pensamiento, explícitamente crítico del marxismo y del liberalismo, seguía los lineamientos socialcristianos del magisterio pontificio del papa León XIII y de sus sucesores. Sin embargo, sus reflexiones también estuvieron influenciadas por el debate intelectual peruano y por sus propias observaciones, acercándose a propuestas reformistas e, inclusive, mostrando una abierta simpatía y cercanía -aunque no una identificación total-con el APRA. A partir de estos escritos, tomando en cuenta sus aportes, e inclusive sus limitaciones y prejuicios, es posible ubicarlo dentro de una tradición eclesiástica de carácter profético que desarrolló una activa defensa de los derechos indígenas que se remonta al siglo XVI y que se prolongó a lo largo del siglo $\mathrm{XX}^{21}$.

Recibido: 09 de junio de 2016

Aprobado: 05 de agosto de 2016

21 Para un estudio de esta tradición eclesiástica indigenista en los casos de Perú y México, véase Marzal (1989). Para analizar este tema en el Perú del siglo XVII, véase Aldea (1993). 


\section{Bibliografía}

ALDEA VAQUERO, Quintín

1993 El indio peruano y la defensa de sus derechos. Lima: Pontificia Universidad Católica del Perú, Fondo Editorial.

ÁLVAREZ-CALDERÓN, Analía

2009 Pilgrimages through Mountains, Deserts and Oceans: The Quest for Indigenous Citizenship (Puno 1900-1930). Tesis doctoral. New York: Stony Brook University.

ARROYO, Carlos

2004 "La experiencia del Comité Central Pro-Derecho Indígena Tahuantinsuyo". Estudios Interdisciplinarios de América Latina y el Caribe. Volumen 15, número 1, pp. $185-208$.

BOLETÍN DEL MINISTERIO DE FOMENTO. SECCIÓN DE ASUNTOS INDÍGENAS

1926 Número 1, pp. 26-27.

CADENA, Marisol de la

2004 Indigenas Mestizos: Raz̧a y Cultura en el Cusco. Lima: Instituto de Estudios Peruanos.

CHANG-RODRÍGUEZ, Eugenio

2009 "José Carlos Mariátegui y la polémica del indigenismo". América sin nombre. Lima, número 13-14, pp. $103-112$

184

DEUSTUA, José y José Luis RÉNIQUE

1984 Intelectuales, indigenismo y descentralismo en el Perú, 18971931. Cusco: Centro de Estudios Rurales Andinos "Bartolomé de las Casas".

DIÓCESIS DEL CUZCO

1923 Constituciones del $5^{\circ}$ Sinodo de la Diócesis del Cuzco. $2^{\circ}$ Después de la promulgación del Código de Derecho Canónico. Celebrado siendo Obispo el Iltmo. i Rmo. Sr. don Pedro 
Pascual Farfán en la Santa Iglesia Catedral, templo de San Antonio de Padua i casa de ejercicios, OFM, del 6 al 12 de diciembre del año del Señor de 1922. Cusco: Tipografía Americana.

FARFÁN DE LOS GODOS, Pedro Pascual

1920 Exhortación pastoral sobre la protección de la raza indígena. Cusco: Tipografía Liga Sagrada.

1918

Exhortación Pastoral que el Iltmo. Y Rmo. Obispo del Cuzco Dr. Pedro Pascual Farfán dirige á los indigenas de su Diócesis al inangurar su gobierno - Ccosco obispucc cunaicusccan llacctampi runancunaman michiccnin casccanta suttinchasccan ppunchaupi. Lima: Imprenta La Providencia.

GARCÍA, Mariano

1914 "Conferencia dada al Círculo de Obreros Católicos el día 22 de marzo de 1914 en el Convento de San Francisco-2". Cusco: Tipografía Americana.

GARCÍA CALDERÓN, Francisco

2001 ElPerú contemporáneo. Lima: Fondo Editorial del Congreso del Perú.

GONZÁLEZ, Osmar

2012 "The Instituto Indigenista Peruano A New Place in the State for the Indigenous Debate". Latin American Perspectives. Issue 186, vol. 39, number 5, pp. 3344.

KATALIN, Jancsó

2007 Indigenismo político temprano en el Perú la Asociación ProIndígena. Tesis doctoral. Szeged (Hungría): Universidad de Szeged.

KLAIBER, Jeffrey. S.J.

1988 La Iglesia católica en el Perú. Lima: Fondo Editorial de la Pontificia Universidad Católica del Perú. 
LARSON, Brooke

2004 Trials of Nation Making: Liberalism, Race, and Ethnicity in the Andes, 1810-1910. Cambridge: Cambridge University Press.

https://doi.org/10.1017/cbo9780511616396

LYNCH, Nicolás

1979 Elpensamiento social sobre la comunidad indigena en el Perú a principios del siglo XX. Cusco: Centro de Estudios Rurales Andinos "Bartolomé de las Casas".

MARZAL, Manuel

1989 Historia de la antropología indigenista: México y Perú. Lima: Pontificia Universidad Católica del Perú, Fondo Editorial.

PANORAMA

1928 'D. Isaías Vargas'. Panorama. Madrid, año VI, número 49.

VALCÁRCEL, Luis E.

1981 Memorias. Lima: Instituto de Estudios Peruanos.

VARGAS BUENO, Isaías

1956 Monografía de La Santa Basilica Catedral del Cusco. Cusco: Editorial Garcilaso.

1953 Conferencias y discursos. Tercera Serie, con apéndice de artículos periodísticos. Cusco: Tipografía Americana.

1948 Recapitulaciones psico-sociológicas de mis apuntes críticos sobre asuntos indigenistas para el II Congreso Indigenistas Interamericano del Cusco, III sección Socio-económica. Cusco: Tipografía Americana.

1947 La democracia auténtica y la Encíclica "Rerum Novarum" de León XIII. Cusco: Tipografía Americana.

1946 Apuntes críticos sobre asuntos indigenistas. Cusco: Tipografía Americana. 
1922 (editor) Actas y documentos del Primer Congreso Interdiocesano de Acción Social del Cusco. Cusco: Tipografía Americana.

VEGA CENTENO, Imelda.

2013 “ «iMi pierna, mi pierna izquierda me duele!» Experiencia religiosa en el proceso de restauración de la imagen del Taytacha Temblores, Cuzco, 2005”. En Judd, Elizabeth, Fortunato Mallimaci (eds.). Cristianismos en América Latina: Tiempo presente, historias y memoria. Buenos Aires: CEHILA - CLACSO.

1993

Pedro Pascual Farfán de Los Godos. Obispo de Indios (1870-1945). Cusco: Instituto de Pastoral Andina. 